\title{
Finalizando um ano atípico de trabalho, mas continuando a construir um Periódico Científico de qualidade
}

\author{
Finishing an atypical year of work, but continuing \\ to build a quality Scientific Journal
}

Anselmo Gomes de OLIVEIRA;

Dâmaris SILVEIRA

Editores-chefe

Com a publicação do último número do volume 32, estamos encerrando um ano muito atípico das atividades do periódico Infarma - Ciências Farmacêutica. Como tradicionalmente fazemos, gostaríamos de registrar nossos sinceros agradecimentos a todos os autores, que nos confiaram os resultados de seus trabalhos; aos revisores ad hoc, aos membros do corpo editorial e aos editores associados, que têm dedicado um tempo precioso para analisar os artigos submetidos e dar os encaminhamentos necessários para o alcance da qualidade desejada; a Diretoria e Conselheiros do Conselho Federal de Farmácia, que sempre tem apoiado, garantindo independência editorial e subsídios para a continuidade da publicação deste periódico. A contribuição de todos tem sido decisiva para o êxito dos trabalhos, sempre na perspectiva do trabalho incansável de todos, em todas as etapas da preparação dos fascículos, para que pudéssemos disponibilizar, aos leitores, os temas mais variados.

Ao longo do ano foram publicados 22 artigos originais, 12 artigos de revisão e 2 notas técnicas, abordando assuntos importantes envolvendo cuidados farmacêuticos a pacientes, estudos de equivalência farmacêutica, estudo de atividade biológica de componentes de plantas medicinais, atenção farmacêutica primária, descarte de medicamentos, qualidade microbiológica em alimentos, desenvolvimento de medicamentos, aspectos relacionados com a qualidade de medicamentos, análise de segurança de fármacos, desenvolvimento de extratos vegetais padronizados, entre outros.

Neste ano de trabalho, completamente atípico, foi necessário que todos se reinventassem com relação à forma de trabalho e, principalmente, quanto à forma de convivência social em razão da pandemia de COVID-19 que se instalou no mundo. Foi um ano de aprendizado, em que muitos aprenderam com o sofrimento, outros aprenderam com a doença e, infelizmente, alguns nada aprenderam.

Mas, depois de um início de incertezas e de informações desencontradas em todo o mundo, a comunidade científica global demonstrou claramente que o conhecimento científico e o trabalho perseverante são fatores relevantes para o domínio dos aspectos mais perversos de qualquer doença, mesmo as provocadas por agentes etiológicos com características desconhecidas. Erros e acertos são esperados em situações dessa natureza e, por meio deles, o conhecimento progride e respostas são encontradas. O ano de 2020, com todos os problemas e angústias, pode ser visto como um grande painel mostrando que a construção do trabalho científico ocorre com trabalho árduo, com sucessos e fracassos e, infelizmente, sob influência política e financeira.

Por meio dos três editoriais anteriores de Infarma - Ciências Farmacêuticas, foi possível observar o domínio temporal das informações em torno da COVID-19. O primeiro abordando as tentativas em torno do tratamento da doença por meio de medicamentos experimentais, principalmente com substancias antivirais (1). O segundo, envolvendo aspectos científicos em torno de ensaios clínicos autorizados no país para demonstrar a eficácia fármacos e de algumas poucas propostas de vacinas contra o vírus (2). E o terceiro abordando o empenho amplo e irrestrito da comunidade científica mundial no desenvolvimento de vacinas com diferentes tecnologias (3). No início, transpareceu uma competição internacional com empresas de vários países competin- 
do para apresentar resultados mais promissores em tempo recorde. Mas, com o passar de pouco tempo, as evidências científicas foram se instalando e os projetos mais promissores foram despontando naturalmente. $\mathrm{Na}$ atualidade, do ponto de vista científico para a controle da COVID-19, não nos parece ser de importância a procedência da vacina. Uma vez demonstradas sua eficácia, segurança e eficiência quanto à produção de anticorpos, estará apta a ser utilizada na imunização da população.

Paralelamente, pesquisadores continuam, de forma isolada ou em colaborações internacionais, a buscar fármacos, de origem sintética ou natural, bem como produtos da medicina tradicional ao redor do mundo, que possam curar ou auxiliar na minimização dos sintomas iniciais da COVID-19 $(4,5)$.

E outro desafio tem mostrado o quão importante é o trabalho científico nesses tempos sombrios de enfrentamento de um agravo de saúde novo e sem precedentes: como identificar e combater as sequelas, ainda pouco conhecidas, que têm assolado os sobreviventes (6). O papel das equipes multidisciplinares em saúde e epidemiologistas é fundamental para a identificação das consequências fisioló- gicas e psicológicas pós-COVID-19, bem como na definição dos cuidados com esses indivíduos $(7,8)$.

Dentro desse contexto, os trabalhos do periódico Infarma - Ciências Farmacêuticas continuaram ininterruptamente levando a seus leitores as informações mais relevantes no campo científico das Ciências Farmacêuticas. Mesmo com as dificuldades inerentes à situação transitória, o sistema de avaliação por pares continuou de forma rigorosa, graças ao trabalho de nossos editores associados. Temos cumprido de forma regular com o cronograma de publicação e, por essa razão, o último número de 2020 deverá ser antecipado em algumas semanas.

Com o dever cumprido em relação aos nossos objetivos, temos a convicção de que o periódico continuará evoluindo e merecendo a confiança dos autores e leitores. Dessa forma, os editores de Infarma - Ciências Farmacêuticas e o Conselho Federal de Farmácia agradecem sinceramente a todos os colaboradores que participaram conosco neste ano e convidamos a todos para a leitura desse último número de 2020 no endereço http://revistas.cff.org. $\mathrm{br} /$ ?journal=infarma.

\section{REFERÊNCIAS}

1. Oliveira AG; Silveira D. Tratamento do Covid-19 com medicamentos experimentais em testes clinicos: desafios e perspectivas. Infarma - Cienc Farmac. 2020;32(1):3-5. DOI:10.14450/2318-9312.v32.e1.a2020.pp3-5.

2. Oliveira AG; Silveira D. Abordagem sobre ensaios clínicos para Covid-19 autorizados no Brasil pela Agência Nacional de Vigilância Sanitária até 30 de junho de 2020. Infarma - Cienc Farmac. 2020;32(2):107-108. DOI: 10.14450/2318-9312.v32.e2.a2020.pp107-108.

3. Oliveira AG; Silveira D. Desenvolvimento de vacinas contra COVID-19. Cooperação ou competição internacional?. Infarma -Cienc Farmac. 2020;32(3):175178.DOI: 10.14450/2318-9312.v32.e3.a2020.pp175-178.

4. McKee DL; Sternberg A; Stange U; Laufer S; Naujokat C. Candidate drugs against SARS-CoV-2 and COVID-19. Pharmacological Research. 2020;157:104859. DOI: 10.1016/j.phrs.2020.104859.
5. Silveira D; Prieto-Garcia JM; Boylan F; Estrada O; Fonseca-Bazzo YM; Jamal CM; Magalhães P O; Pereira E O; Tomczyk M; Heinrich M. COVID-19: Is there evidence for the use of herbal medicines as adjuvant symptomatic therapy? Frontiers Pharmacol. 2020;11:1479. DOI: 10.3389/fphar.2020.581840.

6. Davido B; Seang S; Tubiana R; de Truchis P. PostCOVID-19 chronic symptoms: a postinfectious entity? Clin Microbiol Infection. 2020;26(11):1448-1449. DOI: 10.1016/j.cmi.2020.07.028.

7. Piedra JMS; Hernández EIR; Cuellar C; Machado VDT. Instrumentos evaluadores de secuelas en pacientes posinfección a la COVID-19. Su utilidad en rehabilitación. Rev Cub Med Fís Rehab. 2020;12(3):1-22.

8. Bhandari S; Shaktawat A; Patel B; Dube A; Kakkar S; Tak A; Gupta J; Rankawat G. The sequel to COVID-19: the antithesis to life. J. Ideas Health. 2020;3(Special1):205-212. DOI: $10.47108 /$ jidhealth. Vol3.IssSpecial1.69. 